Departamento de Historia Universidad de Santiago de Chile

Revista de Historia Social

y de las Mentalidades

Volumen 25, $\mathrm{N}^{\circ} 1,2021: 153-186$

Issn Online: 0719-4749

\title{
ESTRATEGIAS DE CONCENTRACIÓN Y RACIONALIZACIÓN DEL PATRIMONIO EN LOS SIGLOS XVI Y XVII: EL CELIBATO Y LA CONSANGUINEIDAD DE LOS MUÑOZ DE OTÁLORA EN LA VILLA DE CARAVACA (ESPAÑA)*
}

\author{
STRATEGIES FOR CONCENTRATION AND RATIONALIZATION OF HERITAGE IN THE \\ 16TH AND 17TH CENTURIES: CELIBACY AND CONSANGUINITY OF THE MUÑOZ DE \\ OTÁLORA IN THE TOWN OF CARAVACA (SPAIN)
}

\author{
DR. JOSÉ ANTONIO MARTÍNEZ MARTÍNEZ** \\ Universidad de Murcia \\ Murcia, España \\ Email: jmm70462@um.es \\ Id-ORCID: 0000-0002-0416-4710
}

\begin{abstract}
RESUMEN
El objetivo de este artículo es analizar las estrategias de concentración y racionalización del patrimonio a través del celibato y de las prácticas matrimoniales de la familia Muñoz de Otálora en la villa de Caravaca. El celibato se presenta como una estrategia en términos de familia frecuentemente empleado por los poderosos para evitar la dispersión patrimonial a través de las renuncias de las legítimas de las monjas y las futuras herencias de los sacerdotes. El matrimonio es analizado en términos de reproducción social y, en el caso de los matrimonios consanguíneos, como una herramienta defensiva del linaje y del patrimonio. A través del
\end{abstract}

\begin{abstract}
The aim of this article is to analyze the strategies of concentration and rationalization of patrimony through celibacy and marriage practices of the Muñoz de Otálora family. Celibacy is presented as a strategy, frequently used by the powerful to avoid the dispersion of patrimony through the resignations of the legitimate nuns and the future inheritances of priests. In contrast, marriage is analyzed in terms of social reproduction and consanguineous marriages, as a defensive tool for lineage and heritage. We can observe that the families of power at the time of choosing a spouse paid as much importance to the place where the
\end{abstract}

* $\quad$ Recibido: 15 de Octubre de 2020; Aceptado: 9 de Febrero de 2021.

** $\quad$ El presente texto se inserta y forma parte del proyecto de investigación: "Entornos sociales de cambio. Nuevas solidaridades y ruptura de jerarquías (siglos XVI-XX)”, HAR2017-84226-C61-P, financiado por el Ministerio de Ciencia y Universidades del Gobierno de España. 
ejemplo de los Muñoz de Otálora observamos que las familias de poder en el momento de escoger un cónyuge prestaron tanta importancia al lugar en el cual radicaban el grueso de las posesiones como a la cuantía de las dotes. La puesta en juego de ambas estrategias, celibato y matrimonios consanguíneos, permitieron la reproducción social de la familia, pero no la reproducción biológica de las principales ramas del linaje.

Palabras clave: Matrimonio; celibato; concentración patrimonial; racionalización del patrimonio; familia bulk of the possessions resided as to the amount of the dowries. The combination of both strategies, celibacy and consanguineous marriages, allowed the social reproduction of the family, but not the biological reproduction of the main branches of the lineage

Keywords: Marriage; Celibacy; Wealth Concentration; Wealth Rationalization; Family

Cómo citar: Martínez Martínez, José Antonio (2021). "Estrategias de concentración y racionalización del patrimonio en los siglos XVI y XVII: El celibato y la consanguineidad de los Muñoz de Otálora en la Villa de Caravaca (España)". Revista Historia Social y de las Mentalidades, 25(1), 153-186. https://doi.org/10.35588/rhsm.v25i1.4679

\section{INTRODUCCIÓN}

Las estrategias de concentración patrimonial empleadas por las familias de poder en España a lo largo del periodo moderno están estrechamente relacionadas con las prácticas hereditarias y con las estrategias matrimoniales. Los vínculos y mayorazgos, popularizados tras las cortes de Toro de 1505, fueron empleados por todas las familias poderosas para legar a uno de los hijos, normalmente el primogénito, el tercio de libre disposición y el remanente del quinto de los bienes libres. Los vínculos y mayorazgos compartían protagonismo con otra figura jurídica de primer orden: las capellanías, institución que igualmente permitía vincular ciertos bienes cargados con un número variable de misas sobre la renta. Estas figuras jurídicas, elementos esenciales de las estrategias de reproducción social, se complementaban con prácticas culturales y biológicas: celibato, matrimonios, trayectorias vitales y sociales, etc.

Los sistemas de herencia, como mecanismo de acceso a los medios de producción, están estrechamente ligados a la organización y al desarrollo de las unidades de residencia: la sociología identifica estas unidades como unidades de producción y de consumo estructuradas a través de las relaciones de parentesco (Devillard 152). El hogar, en sentido espacial, es el lugar físico de residencia de la familia (Reher 59-75). La casa, entendida como la suma intergeneracional del capital honorífico y del patrimonio material, se incardina en el linaje (grupo familiar 
extenso de descendencia unilineal) para afrontar los retos económicos, políticos y sociales. El hogar está limitado por las barreras físicas espaciales, pero la casa y la familia se proyectan al exterior a través de relaciones sociales y económicas, de parentesco, de vecindad y de amistad (Chacón, "La historia" 5-20).

La familia se constituye a través de un contrato (tan solo tenía validez jurídica cuando era sancionada por el sacramento del matrimonio), generalmente plasmado en detalladas capitulaciones matrimoniales, entre dos personas que a su vez pertenecen a una casa, a una familia y a un linaje. La relación de los individuos con su linaje era realmente lo que proporcionaba una identidad propia, al menos en las familias privilegiadas (Stone 23). El núcleo central de la familia está compuesto por el padre de familia, máxima autoridad de la casa, por la esposa y por los hijos. Los parientes son aquellos a quienes por los vínculos existentes de unión se les reconocían los derechos de lealtad, obediencia y apoyo (Stone 23). No obstante, la familia en términos extensos hay que entenderla como el conjunto de personas que viven bajo el mismo techo, aunque no presenten vínculos de parentesco (Chacón, "Familia" 51-66).

El matrimonio era un momento crucial en la trayectoria social del individuo y precisamente por eso era objeto de meditadas estrategias articuladas por y para la familia. La Iglesia trató de regular y ejercer el control sobre los matrimonios y su penetración en la familia para distribuir el poder en la sociedad y para incrementar su propio patrimonio material a expensas de las familias y de los grupos de parentesco (Goody 25; Ghirardi 145). El catolicismo emanado de Trento limitaba la procreación y la sexualidad a las relaciones entre cónyuges, consagrando el matrimonio religioso como el único válido y aceptado por la Iglesia y por el Estado para la reproducción biológica (Ghirardi 147).

Desde la perspectiva social, el matrimonio responde a determinadas estrategias orientadas al aumento del capital relacional familiar, pero en la toma de decisiones el papel primordial lo jugaba el factor económico. El matrimonio permitía el trasvase de bienes entre familias a través de la dote, de las arras y de las donaciones propter nupcias, por ello, desde la perspectiva económica entraban en juego factores como la cuantía de la dote o el lugar donde radicaban el grueso de las posesiones familiares. Lo que podríamos denominar racionalización del patrimonio era tan importante como la cuantía de los bienes aportados a la nueva unidad familiar, al menos eso es lo que se desprende de las prácticas y estrategias nupciales de la familia Muñoz de Otálora. Las prácticas matrimoniales consanguíneas en ocasiones también responden a estas estrategias de concentración y racionalización del patrimonio: se renunciaba a ampliar el capital relacional de la familia pero se conseguía evitar la dispersión de los bienes y favorecía la reunión de las herencias de los antepasados. El celibato, a 
través de la clausura o de la carrera eclesiástica, era otro factor importante de concentración patrimonial, articulado en torno a la renuncia de la legítima y de la herencia a percibir de personas que, al menos teóricamente, dada su condición religiosa, no podrían engendrar descendencia.

Al igual que ocurría en Cataluña con el sistema del "hereu" o de heredero único, la institución del mayorazgo permitía que las familias castellanas concentraran gran parte del patrimonio familiar en un solo hijo, normalmente el primogénito, mediante las mejoras del tercio y quinto de los bienes, quedando el resto de hermanos únicamente como herederos de sus correspondientes legítimas. Sin embargo, en muchas ocasiones, como muestra Ferrer para el caso concreto de Cataluña, los segundones trataban de evitar el descenso social a través de diversos mecanismos: el control de acceso al matrimonio mediante la edad, el ahorro de las dotes por la vía del celibato o el pacto de retorno de las dotes (Ferrer, "Sistema hereditario" 54), optando los segundones de los grupos sociales más acomodados por el celibato eclesiástico (Ferrer, "Segundones" 95). En Castilla ocurría algo parecido con los segundones con escasos recursos económicos: o bien tomaban los hábitos o bien retrasaban el acceso al matrimonio y emprendían la carrera de la milicia. Las familias de las élites urbanas con suficientes recursos, caso de los Muñoz de Otálora, solían enviar a los segundones a los colegios mayores como plataforma de ascenso y promoción social a través del acceso a las reales audiencias y a los consejos del reino.

La familia Musso Muñoz de Otálora dominó durante buena parte del periodo moderno la villa de Caravaca, ampliando incluso sus áreas de influencia y expansión económica a las villas cercanas. La villa de Caravaca era una encomienda de la orden de Santiago en el noroeste del reino de Murcia, dominada a principios del siglo XVI por los marqueses de los Vélez y a lo largo del siglo XVII por los nobles genoveses y por el conde-duque de Olivares. Los recursos económicos de los Muñoz de Otálora procedían especialmente de tres fuentes principales: la ganadería, de la que extraían abundantes beneficios mediante el abastecimiento de las carnicerías públicas y el comercio de lanas, la imposición de censos y juros y la posesión de abundantes tierras de regadío y secano en la huerta y en el campo de la villa.

Contaban con abundantes oficios de regimiento, tanto en Caravaca, donde también controlaban el oficio de alférez mayor, como en Lorca y Murcia. Además, la familia disfrutaba de un amplio capital relacional situado tanto en las reales audiencias como en los principales consejos del reino. Ganaron ejecutoria de hidalguía, vistieron hábitos de la orden de Santiago y de Alcántara, estudiaron en los colegios mayores y accedieron al aparato burocrático y jurídico de la monarquía. Alonso Muñoz, por ejemplo, fue miembro del consejo de Indias y 
Alonso Muñoz de Otálora, su hijo, llegaría a ser Alcalde de Casa y Corte. Las siguientes generaciones incluso ocuparon el oficio de caballerizos de la reina. En definitiva, nos encontramos ante una familia de poder (algunos testimonios del siglo XVII coinciden en señalarla como la más rica del reino de Murcia) que supo aprovechar sus contactos en la villa de Caravaca y en la corte para ascender socialmente y enlazar con destacadas familias tituladas. De hecho, aunque el siglo XVIII su patrimonio material y simbólico pasó a poder de otras familias, podemos considerarla como una familia trampolín: tanto los Uribe, como los Cañaveral o los Melgarejo, herederos de su patrimonio, obtendrían posteriormente títulos nobiliarios. Serían, no obstante, las luchas banderizas que se prolongaron durante buena parte de los siglos XVI y XVII lo que condicionaría las estrategias matrimoniales y de reproducción social de la familia durante buena parte del periodo moderno.

En efecto, la familia Musso Muñoz o Musso Muñoz de Otálora, emplearía desde finales del siglo XVI una clara estrategia matrimonial defensiva y consanguínea, mediatizada en cierto modo por las luchas banderizas que mantenían con el resto de familias notables de la villa de Caravaca por cuestiones relacionadas con las preeminencias anejas al oficio de alférez mayor, patrimonializado por Francisco Musso Muñoz en 1558. En un primer momento, optaron por ampliar horizontes contrayendo matrimonios con familias de poder foráneas y posteriormente intentaron salvaguardar el patrimonio y defender el linaje empleando una pronunciada estrategia matrimonial consanguínea. La familia Musso Muñoz de Otálora combinaría estas prácticas matrimoniales consanguíneas con el celibato, especialmente de las doncellas de la familia.

\section{EL CELIBATO}

Una de las principales características distintivas de las estrategias de reproducción social de gran parte de las aristocracias europeas reside en el hecho de excluir del mercado matrimonial a gran parte de su filiación legítima, amparándose en prácticas ancestrales o en estrategias de reproducción social, cultural o biológica (Monteiro 921-950). El celibato dentro de la tradición judeocristiana debemos entenderlo como la obligación de no casarse y de no hacer uso del matrimonio que se hubiere contraído previamente, normativa que quedaría fijada por escrito en el siglo IV mediante los cánones emanados del concilio de Elvira (Stickler 22) y posteriormente por el segundo Concilio africano del año 390, quedando posteriormente incluida en el Código de los Cánones de la iglesia africana (Stickler 24). A pesar de las distintas disposiciones 
conciliares (incluidas las del IV concilio de Letrán), lo cierto es que los clérigos seguirían manteniendo relaciones sexuales a lo largo de toda la Edad Media. Las reiteradas denuncias relativas a la existencia de barraganas y de hijos de clérigos en los concilios y sínodos bajomedievales (Arranz 27) son una prueba evidente de esta realidad social que incluso se mantendría hasta bien avanzado el periodo moderno.

En Castilla, desde el punto de vista social, el celibato era una forma más de favorecer la desigualdad sucesoria auspiciada por las mejoras de tercio y quinto y por los mayorazgos, al igual que los factores que regulaban la cuantía de la dote nupcial, la cual debía ajustarse teóricamente a la calidad de los cónyuges, a la hacienda del padre y al número de hijos (Ramos, Familia 234). Las dotes que las familias aportaban para el ingreso de algunas de sus hijas en religión eran infinitamente menores que las que debían otorgar para lograr un matrimonio homogámico o hacia arriba. En la primera mitad del siglo XVIII casar a una hija en Portugal era más caro que dotarla para que ingresara en una orden religiosa (Monteiro 939). En España también era más rentable para los bolsillos de las élites enclaustrar a una hija en un convento que dotarla con el dinero correspondiente a la "calidad" que la familia tenía o pretendía representar, circunstancia que se observa fácilmente cuando ponemos en relación la cuantía de las respectivas dotes.

A finales del siglo XVII y a principios del siglo XVIII, por ejemplo, las religiosas que profesaban en el convento de San José de Monjas Carmelitas Descalzas de Caravaca, cabeza de encomienda de la orden de Santiago en el noroeste del reino de Murcia, solían aportar una dote que oscilaba entre los $700 \mathrm{y}$ los 1000 ducados (en ocasiones más), sin contar otros 200 ducados que añadían para ajuar y para alimentos. Las capitulaciones matrimoniales y las cartas de dote de las mujeres de las élites urbanas de Caravaca muestran unos niveles muchísimo más elevados: en 1713 Catalina de Uribe Yarza, esposa de Francisco Musso Muñoz de Otálora, por ejemplo, aportó a su matrimonio una dote algo superior a los 59.530 reales en joyas, dinero y ajuar (AGM, Not. 7432, fols. 60r/67r). Un año antes, Dionisia de Jesús, de 18 años de edad, hija de Baltasar Melgarejo y Fontes y de Catalina de la Osa y Patiño, destacados personajes de la oligarquía murciana, profesó en el convento de San José de Caravaca aportando una dote de 10.000 reales a los que se sumaron otros 2.200 reales para ajuar y alimentos (AMC, Libro de las profesiones de monjas del Carmen de Caravaca. fol. 51r). La disparidad de dotes entre mujeres de idéntico o muy parecido estatus social es ciertamente significativa.

La alta aristocracia portuguesa muestra unas tasas de celibato ligeramente inferior al 50\%, al menos para la segunda mitad del siglo XVII (en la segunda 
mitad del siglo XVIII se aprecia un descenso considerable del celibato) casi un tercio de los hijos e hijas siguieron la carrera eclesiástica, principal destino de las hijas solteras y de los segundogénitos (Monteiro 931). Cifras parecidas se observan en ciudades italianas, como Florencia o Génova, aunque tanto la alta nobleza francesa (duque y pares de Francia) como la inglesa, presenta tasas inferiores de celibato definitivo (Monteiro 932).

El destino eclesiástico a que las grandes casas nobiliarias portuguesas "condenaban" a buena parte de sus hijas venía motivado, según las mordaces críticas de los moralistas, por la falta de dinero para ofrecer una dote para casar como era conveniente (Monteiro 942). En España también existía una cierta disparidad entre el estatus y el dinero disponible de las grandes y pequeñas casas nobiliarias, pero se conjugaban con otros factores sociales, culturales y políticos.

El celibato hay que entenderlo en términos de estrategias de familia, aunque no se debe olvidar que las vocaciones eran frecuentemente alentadas por un ambiente completamente impregnado de religiosidad. En cualquier caso, la familia impone actuaciones que son asumidas por los sujetos con naturalidad, aunque en no pocas ocasiones se detectan casos de hombres y mujeres que serán inclinados al estado eclesiástico de manera violenta o forzosa (Irigoyen, "Bajo el manto" 250).

Domínguez Ortiz expuso una amplia gama de causas de ingreso en el clero: vocación, desengaños amorosos, evadirse de las cargas fiscales y militares o asegurarse un medio de subsistencia (Domínguez 387). En cualquier caso, parece que los más frecuente era que el ingreso en la iglesia viniera impuesto, estimulado o condicionado de algún modo por las familias (Irigoyen, "Bajo el manto" 250)

En otras ocasiones, los ingresos en conventos y monasterios venían forzados por las propias instituciones reales o religiosas. Las mujeres adúlteras, según la legislación castellana, podían ser condenadas a reclusión perpetua en un monasterio. La condición femenina en el adulterio era un agravante: objeto de represiva discriminación (Gacto 24-32). Algunos monasterios se vieron obligados a acoger a mujeres penitentes, especialmente adúlteras, para proteger el orden moral, guardar las apariencias y convertirlas en dóciles religiosas profesas (Morand 50). Las adúlteras gaditanas, por ejemplo, permanecían bajo custodia en la "Casa de Arrepentidas" y posteriormente se trasladaban a algún convento de la diócesis, ya fuera para profesar, ya fuera de forma temporal (Morand 56).

La vocación, evidentemente, también jugaba un papel primordial a la hora de los enclaustramientos conventuales, especialmente en un ambiente social impregnado de religión y donde la doctrina contrarreformista machacaba a diario las "verdades" de la fe. El propio cristianismo era para los tratadistas un 
rasgo distintivo nobiliario. El origen de la nobleza como grupo social se situaba en su concepción cristiana (Aguilera y Guillén, 98). La contrarreforma impregnó a todo el espectro social de una abigarrada mentalidad religiosa y espiritual.

En este contexto surge la figura de Santa Teresa de Ávila y su reforma carmelitana. La figura de Santa Teresa, a través de sus escritos místicos y de su labor reformadora, fue fundamental para el desarrollo de la devoción moderna caracterizada por el recogimiento, la vida contemplativa y una relación más íntima con Dios a través de la oración (Ramos, "Las huellas" 70). La obra reformista de Santa Teresa, inspirada por la gran devoción a la humanidad de Cristo y su pasión, fue de hecho la introducción de una nueva evangelización que alentaba a vivir la vida con radical pobreza, amor fraternal y con sencillez de Corazón (Sequeira 1104).

El camino espiritual de Santa Teresa transita por la vida monástica como un reflejo del estilo contemplativo de la vida cristiana, consistente en apartarse de la vida secular y temporal para dedicarse a Dios (García 523). A través de las Constituciones impulsó y reguló un rígido estilo de vida monástico caracterizado por la búsqueda de un "camino de perfección". Los religiosos del periodo moderno mantenían la firme convicción de pertenecer a la familia religiosa de su orden, generándose al fin una relación de maternidad de las monjas y de los frailes con la fundadora (Egido 413). Los esfuerzos y gestiones de Santa Teresa y el espíritu contrarreformista, a pesar de las rígidas y austeras reglas de la reformada orden carmelitana, propiciaron la fundación de numerosos conventos en la mayor parte de los territorios de la monarquía hispánica, extendiéndose a Francia a comienzos del siglo XVII, nutriendo las principales corrientes de piedad del espíritu místico y asentando las bases de las grandes creaciones religiosas de la época (Lortz 242).

La teatralización de la religión (especialmente de la Pasión de Cristo) y el fervor con que se recitaban los sermones generaban sincera devoción entre los fieles que acudían a las procesiones y funciones del Vía Crucis o a la iglesia. Esto fue lo que ocurrió, según relata la propia Santa Teresa, con las primeras monjas que profesaron en el convento de San José de la villa de Caravaca. Tres doncellas de las principales familias de la villa se enclaustraron un día de marzo de 1575 en las casas de Catalina de Otálora, viuda del licenciado Alonso Muñoz, del consejo de Indias, tras "un sermón que oyeron a un padre de la Compañía de Jesús" (De Jesús 233). Catalina de Otálora se ofreció a albergarlas y a sustentarlas en su casa hasta que se realizaran todas las gestiones necesarias para fundar un convento reformado, facilitándole los medios necesarios para hacer llegar a Santa Teresa sus pretensiones (Melgares y Martínez 65) Según relata la santa, la fundación era pretendida por "los más principales caballeros de aquella villa" (De Jesús 234). 
Las tres doncellas eran doña Francisca de Sahajosa, doña Francisca de Cuéllar y doña Francisca de Tahuste, nieta y bisnieta respectivamente de Pedro Muñoz "el viejo", patriarca de los Muñoces. Catalina de Otálora, viuda del licenciado Alonso Muñoz, del Consejo de Indias, fue una pieza clave en la fundación del convento, aunque finalmente no obtuvo el título de patronato. Rodrigo de Moya, padre de Francisca de Cuéllar, mantuvo correspondencia con Santa Teresa y es posible que también tratara de hacerse con el patronato del convento. Santa Teresa precisa que era un gran siervo de Dios y un hombre de mucha prudencia. Aunque se mostraba reacia a aceptar los bienes materiales de la nobleza y de la corona, lo cierto es que el convento caravaqueño, al igual que el de Soria o el de Palencia (Manero 826), fue fundado gracias a las rentas y a las dotes prometidas por las principales familias de la villa, si bien ninguna de ellas ejercería el derecho de patronato.

Los motivos que las religiosas adujeron para la fundación del convento eran claros, precisos y contundentes:

por quanto en esta dicha villa hasta agora no a avido ni ay ningun monasterio de monjas, e siendo, como es, tan prinçipal y de tanta vecindad e calidad e donde ay munchas mugeres doncellas e prinçipales que desean dexar el estado secular e meterse en religión, se sirbiria mucho Nuestro Señor que en esta dicha villa se hiciese en fundase una casa e monasterio de monjas. (AGM, Not. 7002, fols. $32 \mathrm{r} / 34 \mathrm{v}$. Poder para la fundación del convento)

No había monasterios de monjas ni en Caravaca ni en otras poblaciones cercanas. Las doncellas que deseaban profesar debían ir a la ciudad de Murcia o a otras villas y lugares con conventos. Las familias de la villa que carecían de los recursos para otorgar dotes conforme a la calidad que se les suponía no podían seleccionar las estrategias de reproducción social apropiadas y en muchas ocasiones las doncellas quedaban finalmente sin tomar estado. Algunas solteronas se hacían beatas y otras permanecían en la casa familiar al cuidado de los padres y de los hermanos. El caso de Isabel Muñoz, hija del alférez Francisco Musso Muñoz y de Catalina Díaz de Villalta, ilustra bien la figura de soltera en casa de las élites urbanas del siglo XVI. Isabel Muñoz y el licenciado Pedro Muñoz quedaron como usufructuarios vitalicios de las casas del vínculo que fundó Francisco Musso por expreso deseo de sus padres. Isabel Muñoz permaneció junto a su hermano hasta su muerte y consiguió amasar una pequeña fortuna a través de los negocios y de las legítimas que le correspondían de sus padres. Desconocemos los motivos de su soltería, aunque es probable que 
guarden estrecha relación con el contexto social y político que vivía la familia y el reino de Murcia: las luchas banderizas.

A partir de 1559 la familia Musso Muñoz y sus aliados se enfrentaron violentamente al resto de familias poderosas de la villa por cuestiones relacionadas con las preminencias anejas al oficio de alférez mayor, despachado en cabeza de Francisco Musso Muñoz gracias a las buenas relaciones que mantenía en la corte con el licenciado Sancho López de Otálora, persona muy cercana al círculo del inquisidor Valdés. Las familias de la villa que ostentaban un estatus semejante, como los Mora, los Melgares o los Robles, pleitearon y se enfrentaron con los Musso Muñoz durante años, circunstancia que imposibilitó que se produjeran alianzas matrimoniales hasta bien entrado el siglo XVII.

Los Musso Muñoz buscaron, por tanto, matrimonios con algunas familias foráneas como los Otálora, los Melgarejo, los Rodríguez, los Girón Cernúsculo o los Sahajosa. Por otro lado, reforzaron la parentela concertando matrimonios consanguíneos. Además, en la capital del reino también había una violenta lucha entre Sotos y Riquelmes desatada a raíz del descubrimiento de una comunidad criptojudía, circunstancia que impidió que muchas familias de poder fueran apetecibles para los presuntos hidalgos debido a sus dudosos orígenes. Además, Francisco Musso Muñoz tuvo una larga descendencia y le resultaba imposible obtener buenos matrimonios para todos sus hijos e hijas. Lo cierto es que Isabel Muñoz tampoco pudo profesar como monja porque a la edad adecuada no existían fundaciones conventuales femeninas en la villa de Caravaca y posteriormente heredaría los bienes de sus padres, quedando finalmente como usufructuaria de las casas vinculadas que la familia poseía en la plaza de la villa.

Catalina Musso Muñoz y Aldonza Muñoz, sus hermanas, sí consiguieron buenos matrimonios. Tal vez Isabel Muñoz sacrificó parte de su hacienda para que sus hermanas pudieran enlazar con familias tan relevantes como los Melgarejo. El sacrificio de Isabel Muñoz por su familia, en cualquier caso, es claro: contribuyó con sus mandas y legados a la fábrica de la capilla y de la reja que la familia poseía en la iglesia parroquial de El Salvador; dejó ordenada una capellanía y fundó una obra pía para que el día de Navidad se distribuyeran cada año veinte ducados en reales entre viudas, huérfanos y pobres necesitados; mejoró a su hermano Gonzalo Muñoz para que pudiera casar con Luisa Rodríguez conforme a su condición y finalmente legó al licenciado Muñoz un oficio de regidor y la heredad del Entredicho, compuesta por casas, pajares, ejidos y eras. Era algo común, en definitiva, que las líneas principales de la familia absolvieran los patrimonios de los colaterales. Evitar la dispersión patrimonial era, desde luego, uno de los principales fines del celibato. 
Francisca de Cuéllar (Francisca de la Cruz) y Francisca Caja de Tahuste (Francisca de San José) profesaron en el convento de San José con veinticuatro y veinticinco años respectivamente. La edad media de acceso al convento para las monjas del coro del convento de San José de Caravaca se situaba a lo largo del siglo XVI en torno los 23,7 años. ${ }^{1}$ La más joven ingresó en 1587 con tan solo diecisiete años: María del Nacimiento, hija de Gonzalo Muñoz y de Luisa Rodríguez. La más longeva se llamaba María de Jesús, hija de Amador de Atienza y de Francisca Guirao, y profesó en 1583 a la edad de treinta años. A lo largo del siglo XVI tan sólo ingresaron dos hermanas legas.

Los conventos fueron lugares privilegiados para representar las experiencias de las mujeres y la identidad nobiliaria mediante aspectos visuales (Blutrach 114), pero también se convirtieron en lugares de represión masculina donde se enclaustraban mujeres con el fin de salvaguardar su propia virtud y el honor familiar (Morand 51). Tras los muros conventuales encontraron refugio las mujeres deshonradas y las adúlteras e incluso las solteras y las viudas. Los monasterios eran, en definitiva, espacios abiertos y permeables (Blutrach 114) y centros de vida religiosa que servían de albergues para niños, de internados para jóvenes o de residencias para ancianas (Vigil 169-170) El sistema hereditario basado en la primogenitura y las prácticas vinculares propiciaron que las hijas que no podían optar al matrimonio ingresaran en el convento como única salida honrosa y económicamente viable (Blutrach 114). Las hijas naturales o espurias de la familia también fueron obligadas a profesar como monjas. Francisco Musso Muñoz de Otálora y Catalina López Muñoz ordenaron que Catalina Muñoz, una niña que se había criado en su casa, tomara el velo prieto e ingresara en el convento de monjas clarisas. Francisco Musso Muñoz dejó quinientos ducados para que tomara estado y Catalina López Muñoz añadió otros trescientos ducados de principal en censos para que con la renta "se regale en dicho conbento" (AGM, Not. 7274, fols. 427r/447). Pedro Muñoz de Otálora, caballero de la orden de Santiago y caballerizo de la reina, también dispuso que su hija natural tomara estado de religiosa: Catalina Muñoz de Otálora finalmente profesó como dominica en el convento de Santa Catalina de Siena de Madrid.

El factor económico fue determinante en el caso de las hijas de Gonzalo Muñoz y de Luisa Rodríguez. El matrimonio procreó un hijo varón, heredero del mayorazgo de Campo Coy, y una abundante descendencia femenina: Luisa, Beatriz, Francisca, María, Catalina, Juana e Isabel. A pesar de los abundantes bienes que poseía Gonzalo Muñoz, era materialmente imposible casar a siete hijas con personajes de

1 Algunos registros no precisan la edad de la profesa. 
igual o superior estatus sin hacer un gasto desmedido. María Muñoz y Catalina Díaz de Villalta, probablemente las hijas de mayor fervor religioso, fueron las escogidas para profesar como monjas en el convento de San José de Caravaca, aunque en un principio también se enclaustró Juana Muñoz (AGM, Not. 7003, fosl. 80r/ 84v), después casada con Luis de Gadea Sahajosa. Gonzalo Muñoz se comprometió a dotar a cada una de sus hijas con seiscientos ducados, a proporcionarles el ajuar adecuado y a darles anualmente doce fanegas de trigo en grano y veinticuatro ducados en dineros para alimentos hasta que hicieran la profesión. Las religiosas, por su parte, se comprometieron a renunciar sus correspondientes legítimas (AGM, Not. 7003 , fol. 83r) y el convento se obligó a conseguir la aprobación y ratificación del provincial en un plazo máximo de un año.

Los datos que nos proporcionan los registros de profesiones de monjas del convento de San José de Caravaca son, en algunos aspectos, incompletos. Durante el siglo XVI el 33\% de las monjas que ingresaron en el convento renunciaron a sus legítimas, mientras que el $40 \%$ no hizo ningún tipo de renuncia. El restante $27 \%$ se corresponde con aquellos registros que no proporcionan ningún dato sobre este particular. Para el siglo XVII la información es todavía más incompleta: en tan solo nueve ocasiones se especifica la no renuncia de la legítima. Sería atrevido concluir que la no especificación es indicativa de renuncia. En cualquier caso, las doncellas de los Muñoces se comprometían a renunciar a sus legítimas ante notario, caso de Catalina Bautista, hija de Gonzalo Muñoz, en 1590, por ejemplo (AGM, Not 7005, fols. 57r/61r). Lo habitual era que otorgaran la escritura ante notario poco antes de profesar: María del Nacimiento hizo donación de sus bienes a su padre un par de meses antes de profesar definitivamente como monja en 1587 (AGM, Not, 7004, fols. 77r/79r).

Al fin y al cabo, lo que Gonzalo Muñoz pretendía metiendo a sus hijas en el convento era evitar la salida de bienes de la familia y ahorrarse una dote cuantiosa para proporcionar buenos matrimonios a sus restantes hijas (AGM, Not. 7004, fols. 76r/v). Consiguió sus objetivos, aunque renunció a ampliar el capital relacional de la familia enclaustrando a dos de sus hijas en el convento de carmelitas descalzas, el resto de su descendencia casó con personajes de similar estatus. Incluso consiguió casar a su hija Isabel con Martín de Agüero, señor de Balazote, entroncando de este modo con señores de vasallos. Los seiscientos ducados de las dotes ofrecidas para sus hijas eran ciertamente asequibles para su bolsillo. Lo habitual era que las monjas profesas renunciaran la legítima en favor de sus padres, aunque también encontramos otro tipo de comportamientos: Inés de Santa Teresa, por ejemplo, renunció en 1676 su legítima en una hermana, tal vez para aumento de su dote (AMC, Libro de las profesiones, fol. 42r). La individualidad a veces se ponía al servicio del colectivo familiar. 
Árbol genealógico 1. Descendencia de Gonzalo Muñoz. Monjas

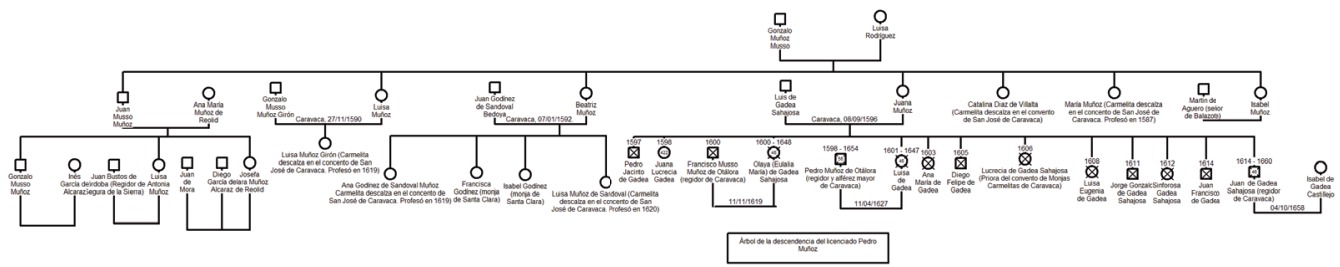

Fuente: Elaboración propia a partir de los registros parroquiales y de los protocolos notariales de Caravaca.

La mayor parte de las monjas de la familia Musso Muñoz profesaron en los conventos de Caravaca, aunque tampoco sobran ejemplos de profesiones en otras villas y lugares. En el siglo XVI casi todas las religiosas que profesaron en el convento de San José eran naturales de la villa de Caravaca, aunque también encontramos algunas monjas legas de la cercana villa de Cehegín: Juana Hernández, por ejemplo, hija de Francisco González y de María Hernández, profesó en 1578 como hermana lega. En el siglo XVII, una vez consolidada la fundación del convento y garantizadas sus rentas, la naturaleza de las monjas profesas se diversificó: encontramos numerosas monjas naturales de Madrid, de Caravaca y de Murcia, aunque también de otras poblaciones, como La Puebla o Villaescusa de Haro.

Catalina Díaz de Villalta, hija de Luis Muñoz y de Úrsula Girón, profesó como monja en el Monasterio de San Antonio de la Madre de Dios de Huéscar en torno al año 1580, ciudad en la que residían buena parte de los parientes de su madre. La cercanía de la familia materna influyó sin duda en la elección del monasterio, pero el factor determinante sería el monetario: Luis Muñoz, su padre, tenía numerosos censos cargados sobre personas de Huéscar y la familia se obligó a pagar la dote con ellos (AGM, Not. 7003, fols. 56r/59). Pedro Muñoz, fiel ejecutor de la villa, que ejerció la curaduría de sus sobrinos durante algunos años, traspasaría finalmente los censos a Francisco Musso Muñoz Girón, regidor de la villa, hermano de la profesa, para hacer el pago al convento. Lo cierto es que los Musso Muñoz emplearon los censos en más de una ocasión para hacer pago de las dotes de las monjas de la familia. Gonzalo Muñoz, por ejemplo, pagó los seiscientos ducados de las dotes de sus hijas con la renta de un censo que tenía impuesto sobre el concejo de Lorca. Las dotes ofrecidas por Gonzalo Muñoz no eran especialmente cuantiosas, sobre todo si las ponemos en relación con otras monjas del estatus de sus hijas: Francisca de San José, hija de Juan Caja y de Ana Tahuste, aportó una dote de 2500 ducados. La media para el siglo XVI, soslayando algunas lagunas documentales, se situaba en torno a los 1000 ducados. 
Las profesiones de monjas también se emplearon para representar el estatus social de la familia, especialmente con el ingreso de las hijas en aquellos conventos que requerían pruebas y limpieza de sangre. Este fue el caso de los Muñoz de Otálora afincados en la corte. Marina Muñoz de Otálora y Antonia Muñoz de Otálora, hijas de Pedro Muñoz de Otálora, caballero de la orden de Santiago, y de María Díaz de Tudanca, profesaron en 1619 como comendadoras de Santiago en el monasterio de Santa Fe de Toledo, tras superar las preceptivas pruebas de ingreso (AHN, OM-Religiosas Santiago, Exp. 466). La reclusión en este tipo de conventos era considerada como actos positivos de nobleza que servían a la familia para justificar futuras pretensiones de hábitos de órdenes militares y de otros honores y privilegios de nobleza.

Otra ventaja asociada estrechamente al celibato era el reconocimiento social que proporcionaba el fuero religioso y el mérito ligado al ascenso de una monja de la familia en la jerarquía conventual (Ramos, Familia 235). En general, podemos considerar los conventos como pequeños espacios que reproducían a escala el sistema social. Los claustros monásticos eran un mundo estrictamente jerarquizado, en el que moraban mujeres de diferentes estamentos que repetían simétricamente la composición de la sociedad civil: religiosas de velo negro, religiosas de velo blanco, legas, etc (Pérez 328).

La madre Ana de San Alberto, enviada directamente por Santa Teresa, fue la primera priora del convento de San José de Caravaca. Posteriormente accederían al priorato Francisca de la Cruz, Francisca de San José y otras monjas estrechamente emparentadas con los Muñoz de Otálora, como la mencionada Catalina Bautista, hija de Gonzalo Muñoz y de Luisa Rodríguez, elegida en el año 1626 (AMC, Libro de las profesiones, fol. 17r). El prestigio y la fama de la familia traspasaban los muros conventuales. Las monjas salidas de las familias de las élites casi siempre eran las que ejercían el oficio de prioras del convento.

Apreciamos un proceso similar en el convento de Santa Clara de Caravaca. Aldonza Muñoz de Otálora, hija de Francisco Musso Muñoz de Otálora, regidor de la villa, y de Catalina López Muñoz, ingresó como novicia en el mencionado convento a principios del año 1611. Francisco Musso Muñoz de Otálora hizo los preceptivos tratados con las monjas (AGM, Not. 7386, fols. 32r/35r) y prometió una dote de ochocientos ducados en censos, el ajuar ordinario y los preceptivos alimentos (AGM, Not. 7386, fols. 36r). Aldonza Muñoz se obligó a renunciar "la herençia, suçesión y legítima" que le pertenecían de sus padres, tomó el velo e hizo profesión de monja en el convento de Santa Clara de Caravaca en 1612 (AGM, Not. 7386, fols. 36r/37v). Tenía diecisiete años cuando ingresó definitivamente en la orden de las clarisas. 
Inés Musso, pariente de Aldonza, profesó en el mencionado convento unos días más tarde, gracias a la aportación económica de Salvador García Calvete, vicario por obispado de Cartagena, su tío (AGM, Not. 7386, fols. 126r/127r). Ambas hicieron juntas el noviciado y ambas profesaron prácticamente al mismo tiempo. La fecha de la profesión de Aldonza Muñoz no fue escogida al azar: el día veinticinco de enero, día de la conversión del apóstol San Pablo. Francisco Musso Muñoz de Otálora y Catalina López Muñoz se obligaron a dar a su hija para alimentos treinta ducados anuales:

Por el mucho amor que tenemos a la dicha nuestra hija y porque son muchas las neçesidades que a las monjas profesas se les ofreçen, así para vestidos de su persona como para otras cossas, y porque dicho convento de presente es nuebamente fundado y su dotación no es bastante para los alimentos de las dichas monjas, comprar ornamentos y otros menesteres (AGM, Not. 7221, fols. 57r/58v).

A finales de 1619 profesaría como monja Inés Muñoz de Otálora, de dieciséis años, hija de Francisco Musso Muñoz de Otálora y de Catalina López Muñoz. Francisco Musso Muñoz de Otálora se obligó a entregar ochocientos ducados de dote y los preceptivos alimentos a condición de que la novicia renunciase sus correspondientes legítimas en favor de Pedro Muñoz de Otálora, su hermano (AGM. Not. 7333, fols. 297r/324v.) Los familiares se preocupaban por el bienestar de los monjas dentro de la clausura y solían dejar rentas y alimentos suficientes para asegurar su sustento después de su muerte. Catalina López Muñoz, por ejemplo, dispuso por su testamento que le dieran anualmente a su hija Aldonza cincuenta ducados de renta en censos, "los mexores que ubiere", para alimentarse y vestirse con la decencia que le correspondía (AGM, Not. 7274, fols. 427r/447). Gonzalo Muñoz, quien en 1625 tenía dos hijas y cuatro nietas en el convento de carmelitas descalzas de la villa de Caravaca, dejó un censo de 200 ducados de principal que tenía sobre Pedro de Mata Monteagudo, regidor de la villa, para que Luis de Gadea Sahajosa, su yerno, distribuyera la renta según las necesidades de cada una de las religiosas (AGM, Not. 7350, fols. 86r/116r). Las cuatro nietas de Gonzalo Muñoz eran Lucrecia de la Cruz, hija de Luis de Gadea y de Juana Muñoz, que profesó en 1624 (AGM, Not. 7348, fol. 194r) y llegaría a ser priora del convento; Ana de Jesús y Luisa de la Madre de Dios, hijas de Juan Godínez de Sandoval y de Beatriz Muñoz, que profesaron respectivamente en 1619 y en 1620 y finalmente Luisa del Espíritu Santo, hija del capitán Gonzalo Muñoz y de Luisa Muñoz, que tomó los hábitos en 1619. Además, Gonzalo Muñoz tenía otras dos nietas en el convento de Santa Clara: 
Francisca Godínez e Isabel Godínez, hijas de Juan Godínez de Sandoval y de Beatriz Muñoz. Ambas monjas profesaron en torno al año 1622 y su abuelo se comprometió a darles ochenta ducados para alimentos (AGM, Not. 7055, fols. 98r/99r).

El convento de Santa Clara estaba situado en las antiguas casas de Ginés de Perea, fundador del monasterio, en la calle de los Melgares, justo al lado de las casas principales de los padres de Aldonza Muñoz. El contacto entre Aldonza y sus familiares era diario y constante. De hecho, Aldonza Muñoz fue la depositaria del testamento in scriptis de su madre. También mantenía relaciones con otros vecinos de la villa: Pedro Alcázar Torrecilla, por ejemplo, se obligó a pagar a doña Aldonza Muñoz de Otálora, monja profesa en el convento de Santa Clara de la villa de Caravaca, 200 reales en moneda de vellón que le debía de prestado (AGM, Not. 7142, fol. 202r/v). El contacto entre las monjas de clausura y el "mundo exterior" era realmente diario, como evidencian diferentes testimonios y creaciones literarias de religiosas del siglo XVIII (Morand 1032). La relación de los Muñoz de Otálora con las monjas de Santa Clara era tan estrecha que incluso llegaron a cederle ciertas habitaciones para ampliar el convento. También era frecuente que los padres de las profesas favorecieran con sus mandas y legados al convento. Francisco Musso Muñoz de Otálora, por ejemplo, legó cien ducados al convento de Santa Clara para que las monjas se hicieran un terno y Catalina López Muñoz, su esposa, dispuso por su testamento que se dieran diez ducados de limosna. Aldonza Muñoz ejerció de abadesa de Santa Clara hasta su fallecimiento. El prestigio y el poder de los Muñoz de Otálora traspasaba las paredes conventuales e iba más allá de sus ansiados oficios de ayuntamiento. El caso del convento de carmelitas descalzas es un buen ejemplo, pero también la figura de Aldonza Muñoz, abadesa de Santa Clara.

En cualquier caso, las monjas, debido a su condición de mujeres, eran consideradas miembros de segunda fila en el seno de una iglesia controlada exclusivamente por los hombres (Morgado 87), aunque evidentemente también desempeñaban una fundamental labor social. Los eclesiásticos, en particular, cuando accedían a grandes dignidades (canonjías, obispados, etc.) y realizaban servicios importantes en favor de los monarcas, engrandecían su casa y su linaje (Monteiro 945). Los familiares participaban del prestigio de los miembros de la iglesia.

Los Muñoz de Otálora utilizaron la iglesia para dar salida a sus hijos naturales o espurios, caso de Jorge Muñoz, religioso de Santo Domingo en el convento de San Esteban de Salamanca, o del vicario Pedro Muñoz de Otálora, pero también como palanca de ascenso y de prestigio social para sus hijos legítimos. Los casos más relevantes son los relativos a los canónigos que la familia introdujo en el cabildo de la catedral de Toledo: eran las canonjías más relevantes del reino y 
además exigían pruebas de limpieza de sangre. Algunos parientes de los Muñoz de Otálora, como los Muñoz de Vizcaya, (Pizarro 594) ya habían superado las pruebas, aunque parece que tanto Diego Muñoz de Otálora como Sancho Muñoz de Otálora, tuvieron algunas dificultades para acceder al cabildo.

Lo cierto es que se puso en tela de juicio su limpieza de sangre y se movieron algunos pleitos. Las canonjías eran cargos de prestigio en el seno de una institución omnipresente en la sociedad del setecientos. En Murcia, por ejemplo, a finales del siglo XVII se observa un cierto proceso de cierre social $\mathrm{y}$ de aristocratización entre los canónigos y las dignidades: en este momento se incorporan varios personajes distinguidos con hábitos militares (Irigoyen, Entre el cielo 218). Los Muñoz de Otálora, pese a las dudas sobre su hidalguía, consiguieron entrar en la institución, guardar las apariencias y mantener indemne su prestigio social. Las carreras eclesiásticas raramente se sustentaban en el propio mérito personal, eran más bien las vinculaciones familiares y las relaciones clientelares las que constituían el factor esencial del ascenso jerárquico y social (Morgado 85).

Diego Muñoz de Otálora, hijo de Pedro Muñoz de Otálora, caballero de la orden de Santiago y caballerizo de la reina, fue el primero de la familia en intentar acceder al cabildo. El ingreso y la defensa de la limpieza de sangre eran cuestiones tan relevantes para el honor del linaje que buena parte de la familia contribuyó económicamente para la defensa de los pleitos y para el definitivo acceso a la canonjía. Gonzalo Muñoz, regidor de Caravaca, prestó "para socorro de los pleytos y gastos que ubo para la canonjía de don Diego", cuatro mil reales (Archivo General de Simancas, CME,130, 34, s. f.); Luis de Sahajosa prestó mil reales y Francisco Musso Muñoz de Otálora otras dos mil reales. Sancho Muñoz de Otálora, quien también tuvo algunas dificultades para acceder al cabildo de la Catedral de Toledo a principios del siglo XVII, gastó cuatro mil ducados de la hacienda de su padre para conseguir finalmente la canonjía. La inversión era costosa pero a la larga resultaba beneficiosa para la familia, rentabilizada en términos económicos y de prestigio social. El sacerdocio, entendido como un bien patrimonial, generó lazos entre la nobleza y la iglesia (Catalán, "El clero" 33). La connivencia con el poder posibilitó que la iglesia como institución y muchos de sus miembros amasaran grandes patrimonios en estrecha contradicción con los preceptos de pobreza evangélica (Catalán, "El clero" 2). Las dignidades y canonjías del cabildo de la catedral de Toledo estaban completamente dominadas por las oligarquías locales y por las familias nobles (Sánchez 31) y además muchos de los miembros del cabildo fueron promovidos a otras esferas de poder, tanto civiles como religiosas (Sánchez 32). La inclusión dentro de este selecto grupo, por tanto, reportaba prestigio social a la familia Muñoz de Otálora. 
Pedro Muñoz de Otálora y María Díaz de Tudanca tuvieron, al menos, ocho hijos: Pedro, Alonso, Diego, Sancho, Martín, Catalina, Marina y Antonia. Tan solo dos hijos, un hombre y una mujer, tomaron estado de casados: Pedro Jacinto Muñoz de Otálora casó en 1625 en primeras nupcias con Micaela de Lara, hija de Juan de Lara y de María de Cardería, y en segundas con Juana María Girón Duque de Estrada y Toledo, hija de García Girón y de María de Meneses y Toledo. Catalina Muñoz de Otálora, la hija mayor, contrajo matrimonio en Granada con Gregorio López de Mendizábal, oidor de la chancillería de Granada, aunque finalmente falleció en 1628 sin dejar descendencia. Martín Muñoz de Otálora falleció sin llegar a tomar estado y el resto de hijos e hijas fueron destinados a la Iglesia. Pedro Muñoz de Otálora, caballero de Santiago y caballerizo de la reina, incluso metería en el convento de Santa Catalina de Siena de Madrid a una hija natural que tuvo antes de contraer matrimonio con María Díaz de Tudanca. La estrategia familiar era clara: pretendía acumular todo el patrimonio en Pedro Jacinto Muñoz de Otálora, caballerizo de la reina y caballero de la orden de Santiago. De hecho, hasta le consiguieron el mayorazgo de prelación femenina que Catalina Muñoz de Otálora, hija del licenciado Alonso Muñoz, había fundado para su hermana en 1615.

Sancho Muñoz de Otálora llevaba un alto nivel de vida. Mantenía numerosos criados, un paje llamado José Serrano y un administrador encargado de los vestuarios de la canonjía. Además, tenía un mayordomo llamado Tomás Calderón encargado de la administración de su casa y hacienda. La relación con su hermano era cercana y constante, al igual que la mantenida con Cebrián Muñoz de Vizcaya, igualmente canónigo de la catedral de Toledo, su pariente. María Orozco, madre de Pedro Jacinto Muñoz de Otálora y Orozco, ejerció de criada de Cebrián Muñoz de Vizcaya en su casa de Toledo, lugar donde "tuvo comunicación, amistad y trato carnal" con Pedro Jacinto Muñoz de Otálora y Tudanca, caballero de la orden de Santiago. Sancho Muñoz prestaba ayuda y favor a sus paisanos de la villa de Caravaca: dispuso por su testamento, por ejemplo, que se le dieran a Pedro de Robles, estudiante que estaba preso, algunos dineros para fenecer cierto pleito que tenía pendiente. Otorgó testamento en 1637 y dejó como heredero universal de todos sus bienes a Pedro Jacinto Muñoz de Otálora, su hermano. También le mandó un caballo que se llamaba Perlilla "por el mucho amor y boluntad que a su merçed e tenido y tengo y por la buena ermandad que tenemos" (Archivo Histórico Protocolos Notariales de Toledo, T. 16939 , fols. $450 \mathrm{r} / 453 \mathrm{v}$ ). Las herencias de los colaterales contribuían a engrosar el patrimonio familiar.

El celibato funcionaba como estrategia de concentración del patrimonio en el pariente mayor de la familia. Se trataba, en definitiva, del objetivo marcado 
por Pedro Muñoz de Otálora y María Díaz de Tudanca cuando decidieron meter en religión a la mayor parte de sus hijos. La propia María Díaz de Tudanca fundaría en 1632 un mayorazgo con facultad real valorado en cuarenta y un mil ducados (Archivo Histórico Protocolos Notariales de Madrid, T. 2054, fols. 235r/250r), llamando a suceder en primer término a Pedro Jacinto Muñoz de Otálora, su hijo, de modo que el susodicho vino a suceder en todos los mayorazgos y vínculos de esta rama de la familia. Consiguió reunir el mayorazgo fundado por Pedro Muñoz "el viejo"; su bisabuelo, así como los fundados por el licenciado Alonso Muñoz, del consejo de Indias, y Catalina de Otálora, sus abuelos paternos. Asimismo, recibió el vínculo del tercio y quinto que fundó en 1626 su padre y el mayorazgo (estaba valorado en casi tres millones de maravedís) instituido por Pedro Díaz de Tudanca, y Marina Núñez Trigueros de Prado, sus abuelos maternos.

Por su parte, Alonso Muñoz de Otálora, hermano de Pedro Jacinto Muñoz, profesó en la orden de clérigos regulares menores en el convento del Espíritu Santo de la villa de Madrid, renunciado previamente a los derechos que tenía para suceder en el vínculo instituido por Catalina Muñoz de Otálora. Los clérigos regulares menores, orden instituida en Nápoles por Agustín Adorno y Ascanio Caracciolo a finales del siglo XVI, cumplían los votos monásticos y se caracterizaban por ser unos sacerdotes activos y ejemplares en el apostolado (Marín 251). El padre Alonso Muñoz de Otálora fue, además, maestro y lector de Teología, Calificador de la Suprema Inquisición desde 1640 y Predicador de su Majestad. Aprobó la tercera parte del Criticón de Baltasar Gracián y las Ideas de Apolo y dignas del ocio cortesano, libro de poemas publicado por Sebastián Ventura de Vergara en 1663, obra dedicada a don Pedro Fernández del Campo, caballero de la orden de Santiago y secretario de Estado en Italia. Alonso Muñoz de Otálora ejerció de apoderado de Pedro Jacinto Muñoz de Otálora y gestionó mediante poderes su hacienda en la villa de Caravaca desde 1637 (AGM, Not. 7278, fols. 1495r/1497v). En 1653 interpuso pleito de tenuta de los mayorazgos de la familia, aunque posteriormente firmó una escritura de convenio con sus parientes para repartirse los bienes vinculados, siendo ratificada y aprobada por el rey en 1656. Finalmente falleció en abril del año 1668.

La estrategia de concentración patrimonial de los Muñoz de Otálora fue errónea. Pedro Jacinto Muñoz de Otálora, alcalde de la Mota del Cuervo y del Puente de Mérida, primogénito de la familia, a pesar de haber contraído matrimonio dos veces no consiguió engendrar descendencia legítima. Tuvo dos hijos naturales llamados Jacinto Bernabé y Pedro Jacinto Muñoz de Otálora, que se criaron en Madrid. La consecuencia directa fue la separación de los bienes vinculados de los Muñoz de Otálora y de los Díaz de Tudanca. La merma 
del capital económico afectó al prestigio de la familia y propició el descenso social de la rama cortesana, aunque las siguientes generaciones consiguieron enlazar con los Valderrama y los Toledo. El padre Alonso Muñoz quedó como administrador de los bienes de mayorazgos pero la mayor parte de los bienes vinculados, como ya expusimos, se los repartieron entre los Sáenz de Navarrete y los Uribe. Los vínculos de los Díaz de Tudanca fueron a parar a María Manuela Díaz de Tudanca, esposa de Francisco Marañón y Goñi, señor del palacio de Marañón y del lugar de San Millán. En 1669 Pedro Jacinto Muñoz y los Díaz de Tudanca llegaron a un nuevo acuerdo para repartirse los bienes vinculados.

El padre Alonso Muñoz de Otálora protegió en todo momento a su sobrino, primero reconociéndolo como hijo natural de su hermano y posteriormente cediéndole el derecho de sucesión de los bienes vinculados de la familia. La función del tío clérigo en el seno de la familia era fundamental en el entramado social del Antiguo Régimen, especialmente si se pretendía hacer carrera eclesiástica (Morgado 85). Los clérigos de la familia también eran los encargados de dotar a doncellas para que tomaran estado de religión o de casada. No faltaban los clérigos que dejaban a sus sobrinas o hermanas religiosas rentas o dineros para sus alimentos y otras necesidades conventuales. Sancho Muñoz de Otálora, canónigo de la catedral de Toledo, por ejemplo, dejó cien ducados a Catalina Muñoz, su hermana, monja profesa en el convento de Santa Catalina de Siena de Madrid.

El clero se caracterizaba por la cercana relación a la familia y actuaba como su protector, acogiendo en su propia casa o favoreciendo con sus influencias y su dinero a los componentes menos favorecidos, como las madres viudas, las hermanas solteras o los sobrinos huérfanos (Morgado 85). El componente femenino en los hogares de eclesiásticos también era ciertamente relevante, al igual que los parientes, los estudiantes, los clérigos de menores órdenes y los pajes (Irigoyen, "Carrera eclesiástica" 279-295). Los encontramos a todos en la casa del canónigo Sancho Muñoz de Otálora: pajes (José Serrano y Pedro Martínez), estudiantes (don Pedro de Robles), criados (Catalina de Paz y Antón Francés), parientes, administradores, etc. Los pajes eran un elemento ostensible de prestigio social, una manifestación tangible del poder del religioso. En ocasiones estaban ordenados de menores órdenes y seguían la carrera eclesiástica (Irigoyen, "Carrera eclesiástica" 288). En líneas generales, el alto clero contribuyó a la formación de nuevos religiosos poniendo a su disposición sus propias redes relacionales como instrumentos para progresar en la jerarquía eclesiástica.

Para acceder al estamento eclesiástico era necesario poseer una renta económica (beneficio) que asegurase la independencia del poder laico y 
garantizase el mantenimiento del clérigo con la decencia debida a su condición (Catalán, "El clero" 4). Los Muñoz de Otálora emplearon sus censos y sus numerosas capellanías para proveer a sus aspirantes a clérigos de unas rentas lo suficientemente importantes para alcanzar con plenitud el sacerdocio o las órdenes mayores. Diego Musso Muñoz de Otálora, colegial mayor en el del arzobispo de Salamanca, hijo de Francisco Musso Muñoz de Otálora, profesó a principios del siglo XVIII las menores órdenes para gozar de las rentas de las capellanías familiares. Los clérigos de menores órdenes no siempre se ordenaban sacerdotes. Era frecuente que finalmente acabasen contrayendo matrimonio. Diego de Uribe Yarza, por ejemplo, clérigo tonsurado con beneficio eclesiástico, casó en México con Ana de Uribe, su prima, hija de José Joaquín de Uribe Castejón y Medrano. En ocasiones fueron los propios aspirantes los que alcanzaron las órdenes menores e instituyeron su propia capellanía: Juan Escagedo Musso Muñoz, por ejemplo, fundó una capellanía con un censo de ciento y veinte ducados de principal (AGM, Not. 7126, fols. 29r/30v). Algunos criados de la familia, como Juan Rodríguez de Celis o Francisco de Gamboa y la Paliza, incluso tomaron las órdenes menores para gozar de las rentas de las capellanías de los Muñoz de Otálora.

El acceso a la iglesia y la carrera eclesiástica formaban parte de las estrategias familiares y estaban condicionadas por la coyuntura y por el contexto social y político (Irigoyen, "Bajo el manto" 250). Los Muñoz de Otálora emplearon esta estrategia exclusivamente a principios del siglo XVII, en un contexto preciso de crisis y de remanente de capital humano del linaje. Estrategias mediatizadas por numerosos condicionantes sociales y políticos. La vocación también fue un factor importante en el acceso al estamento eclesiástico, aunque algunas veces la ordenación simplemente respondía a una promesa o voto realizado en un momento crítico o dificultoso de la existencia. Era algo común entre los soldados y los milicianos hacer promesas y juramentos de entrar en religión o profesar en algún convento. Así lo hizo, por ejemplo, el capitán Andrés de Mora, el cual tomó los hábitos en el convento de San Francisco de la villa de Moratalla y a los ocho o diez días se salió, por cuya razón en la villa le llamaban Andrés "el fraile" (AHN, OO_MM. AHT. Exp. 15959, s. F). Tal vez a este mismo propósito responda el ingreso de Luis Muñoz Girón en la orden de San Bernardo y su profesión en el convento de Valparaíso a principios del siglo XVII (AHN, OO_MM. AHT. Exp. 9412., s. F). También era frecuente que los viudos tomaran los hábitos e hiciesen los votos una vez garantizada su descendencia (Ramos, Familia 237): este fue el caso, por ejemplo, del doctor Juan de Uribe Yarza. 


\section{LA CONSANGUINIDAD Y LA CONCENTRACIÓN PATRIMONIAL}

Los condicionantes sociales, políticos y económicos fueron factores esenciales en las estrategias matrimoniales de las familias de poder a lo largo de todo el periodo moderno. El objetivo final era mantener el estatus, conservar y aumentar el poder económico, estrechar lazos con otras familias poderosas $\mathrm{y}$, en definitiva, aumentar el capital relacional de la familia y mantenerse arriba (Hernández y Molina 219-235). Las familias de poder contaban con tres tipos de estrategias a la hora de seleccionar y planificar los matrimonios: los matrimonios desiguales o hacia bajo, frecuentes cuando el prestigio social de la familia no era proporcional al abolengo y se necesitaban nuevas inyecciones patrimoniales (Chacón y Méndez 84-85); el matrimonio homogámico con familias que poseyeran un estatus y un poderío semejante o superior; finalmente el matrimonio consanguíneo, que permitía a la familia replegarse sobre sí misma y evitar la dispersión patrimonial.

Podemos interpretar el matrimonio entre parientes próximos como una consolidación de las relaciones más amplias entre parientes, fórmula que permitía la unidad de la familia y de las propiedades. La iglesia se opuso más o menos enérgicamente a este tipo de matrimonios porque amenazaban su creciente control sobre la población y la capacidad para recibir donaciones (Goody 40). Las prácticas matrimoniales consanguíneas fueron utilizadas con mayor o menor grado de frecuencia por las familias de élites para mantener su cuota de poder y el estatus alcanzado, evitar la dispersión patrimonial y reproducir su condición social privilegiada. Al fin y al cabo, les permitía conservar los bienes en el seno del linaje y seguir detentando los atributos honoríficos y de prestigio diferenciales. No obstante, diversos estudios sugieren que los matrimonios entre parientes nunca fueron la tónica dominante, ni en España ni en otros países del occidente europeo, como Francia e Italia, al menos durante el siglo XVIII (Gausse 31-61). De hecho, según las estadísticas que nos proporciona Gausse poniendo en relación las dispensas obtenidas con datos poblacionales, en España, alrededor del año 1770, tan solo se celebraba un matrimonio consanguíneo por cada 25000 o 30000 habitantes (38).

Las estrategias nupciales de las familias de las élites de poder transitaron por dos caminos diferentes: las familias que disfrutaban de una posición elevada en la jerarquía social intentaron buscar matrimonio con personas con las que ya mantenían lazos de parentesco, como instrumento para conservar el estatus adquirido; las familias que se encontraban en pleno proceso de promoción social prefirieron ampliar sus redes relacionales practicando políticas matrimoniales más abiertas, enlazando con múltiples familias, como vía para consolidar la posición y ser reconocidos y admitidos como miembros del grupo (Rodríguez, 
"El poder" 15-34). Los estudios prosopográficos demuestran que las prácticas consanguíneas nunca estuvieron muy extendidas, como evidencian los casos de los regidores de Madrid (tan solo afectó al 5\% de los regidores) (Hernández 168) o los del corregimiento de Chinchilla Villena (Molina 228).

La Iglesia procuró alentar la libre elección de cónyuge de las partes, pero también se preocupó de establecer los grados aceptables, tanto en materia de sangre como de afinidad y de parentesco espiritual. Los impedimentos podrían salvarse ganando dispensa en los tribunales romanos, previo pago del importe de dinero estipulado. En las causas que motivaron estas solicitudes de dispensas intervienen y se conjugan tanto factores geográficos, como sociales, culturales y económicos. Las causas más frecuentemente aducidas por los solicitadores nos remiten a la estrechez de lugar (Bestard 107-156), especialmente visible en zonas rurales de escasa población y de difícil acceso, que presentaban ciertamente una oferta matrimonial más bien reducida, dejando poco margen de maniobra a las familias a la hora de buscar cónyuges fuera del parentesco. Condicionantes geográficos, sin duda, pero amparados en prácticas culturales y sociales aceptadas por la comunidad y permitidas, en mayor o menor grado, por las autoridades eclesiásticas y civiles. En el caso de las familias de poder, más que los condicionantes geográficos, jugaron un papel decisivo otros factores directamente relacionados con sus estrategias de conservación del patrimonio y de mantenimiento del estatus social adquirido, estrechamente interconectados ambos, como resulta evidente, con las estrategias de reproducción social desplegadas en cada determinado momento, independientemente de las tretas jurídicas que emplearan para conseguir que se les despacharan las dispensas. De hecho, estas familias poderosas aducían como motivo principal para solicitar la dispensa de consanguinidad ciertos condicionantes sociales, apelando para ello a la nobleza y a la conservación del linaje y de los bienes de la casa. Así, por ejemplo, Luis de Gadea Sahajosa y Juana Muñoz, parientes en tercer grado, no dudaban en sugerir en sus capitulaciones matrimoniales, otorgadas en la villa de Caravaca el día seis de septiembre de 1595, que

las causas que se an de poner para alcançar la dicha dispensación son que el dicho don Luis de Gadea es mayorazgo y por ser noble e hijodalgo y por ser como la dicha doña Juana Muñoz es también hijadalgo se a de suplicar a Su Santidad les conçeda la dicha dispensación por conserbar la nobleça y linpiença de su linaje. (AGM, Not. 7062, fols. 234r/236).

La familia Muñoz de Otálora practicó desde las últimas décadas del siglo XVI una estrategia de matrimonios consanguíneos, primero con los Otálora, 
estrechamente ligados a los diversos consejos de la monarquía, y posteriormente con los Gadea, con los que ya mantenían vínculos de parentesco. De hecho, la mayor parte de los nietos de Francisco Musso Muñoz y de Catalina Díaz de Villalta escogieron matrimonios dentro de la parentela. Lo importante era salvaguardar el patrimonio y mantener unida la familia en un contexto de luchas banderizas contra buena parte de las familias de poder de la villa. Paralelamente practicaron una estrategia de compadrazgo exclusivamente dentro de la parentela. Conviene detenerse en el matrimonio efectuado en 1589 entre Francisco Musso Muñoz de Otálora, hijo del licenciado Pedro Muñoz y de Inés de Otálora, y Catalina López Muñoz de Villalta, hija de Diego López Baladejo y de Aldonza Muñoz. Francisco Musso, hijo segundogénito del licenciado Pedro Muñoz, y Catalina López eran primos hermanos.

Árbol genealógico 2. Relaciones consanguíneas entre los Muñoces y los Otáloras

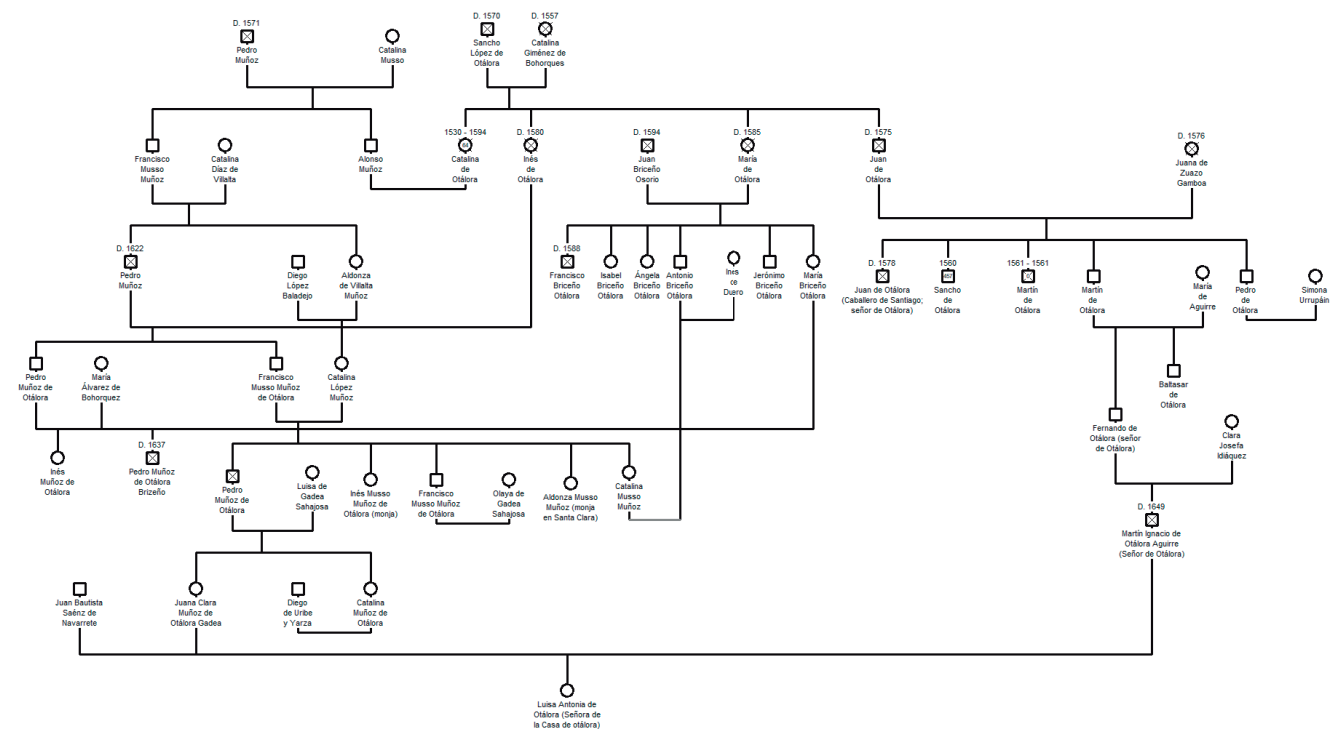

Fuente: Elaboración propia a partir de los registros parroquiales y de los protocolos notariales de Caravaca.

Tras el fallecimiento sin descendencia de Diego López de Villalta, primogénito, Catalina López heredó el mayorazgo instituido por sus padres. Francisco, segundón de la línea principal de los Muñoz de Otálora, estaba apartado de los mayorazgos y vínculos principales de la familia, pero recibió una 
buena dote, en la que se incluía un oficio de regimiento y unas casas principales en una de las mejores calles de la villa. Estas prácticas consanguíneas hay que ubicarlas en el contexto de racionalización del patrimonio. La opción de desposar a uno u otro pariente no se dejaba al azar, casi siempre respondía a una estrategia meditada. Solían buscar oficios de poder y bienes que lindaran con las posesiones de uno y otro cónyuge como medio para reagrupar las haciendas divididas en los anteriores repartos de herencias. La elección fue idónea: Pedro Muñoz de Otálora, hijo de Francisco Musso Muñoz de Otálora y de Catalina López Muñoz, heredó todos los vínculos y mayorazgos de la familia tras el fallecimiento de Pedro Muñoz Briceño, mayorazgo, sin descendencia en 1637.

Pedro Muñoz de Otálora, alférez mayor de Caravaca, era un hombre muy poderoso, con "mucha mano en la república y vecinos" de la villa y uno de los hombres más ricos y hacendados del reino de Murcia. Algunos testimonios de mediados del siglo XVII lo presentan como "poderosísimo y el más rico de este reyno" según pública voz y fama (AHN, CONSEJOS, 25857. Exp. 5. 230r/v). Otros lo definen como poderoso, batido en duelo, diestro en el manejo de la espada y atemorizador de sus contrarios y enemigos. No les faltaba razón a los testigos que depusieron sobre sus riquezas y posesiones.

Árbol genealógico 3. Descendencia del licenciado Pedro Muñoz, alférez

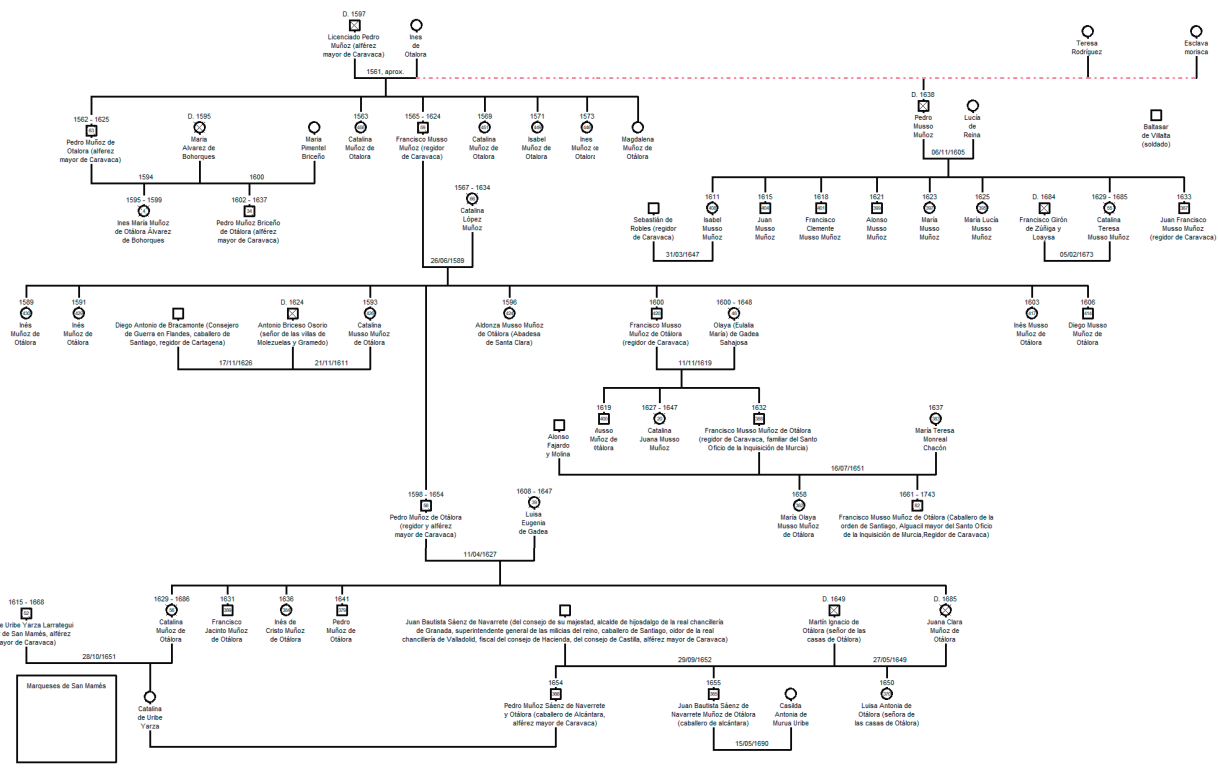

Fuente: Elaboración propia a partir de los registros parroquiales y de los protocolos notariales de Caravaca. 
Pedro Muñoz de Otálora incrementó la hacienda familiar realizando diversas compras de tierras y de casas en el campo y en la huerta de la villa desde fechas anteriores a la herencia: en 1628, por ejemplo, compró a Gonzalo Contreras de Balboa y a Francisca Godínez, vecinos de Veas, sus parientes, la mayor parte de la hacienda que poseían en Caravaca, en la que se incluían, entre otros bienes, diversas heredades de tierra blanca y de moreras en la huerta de la villa y unas casas en la calle de Juana Noguera (AGM, Not. 7268, fols. 80r/85r y $87 \mathrm{r} / 89 \mathrm{v}$ ). No era algo novedoso en la familia, las estrategias de racionalización $\mathrm{y}$ concentración del patrimonio familiar fue una práctica habitual tanto en el siglo XVI como en las centurias siguientes. Las mujeres de la familia que contraían matrimonio con caballeros foráneos solían vender sus herencias a sus parientes más cercanos: ya en 1601 Francisca Muñoz, esposa de Luis de Bedoya Vozmediano, vendió a Francisco Musso Muñoz de Otálora, regidor, su cuñado, la mitad del cortijo del Campillo que había heredado de Diego López Baladejo y de Aldonza de Villalta, sus padres (AGM, Not. 7199, fols. 136r/140r). La otra mitad del cortijo del Campillo era propio de Catalina López Muñoz de Villalta, esposa del mencionado Francisco Musso. En definitiva, estas estrategias de compraventa estaban orientadas a concentrar de nuevo el patrimonio que había quedado dividido en las herencias. Existe un claro predominio del tronco familiar, en este caso de las líneas mayorazgas de la familia, sobre los restantes núcleos que lo componen: la propiedad tiene una mayor concentración relativa en las líneas principales que en los núcleos que componen el linaje, más sujetos a la dispersión (Levi 171).

También se trataba de evitar la salida y la dispersión de bienes del linaje: en 1631, por ejemplo, Sancho Godínez de Sandoval, vecino de Veas, con licencia de Isabel Godínez, su mujer, vendió todos los bienes que había heredado de Gonzalo Muñoz y de Luisa Rodríguez, sus abuelos, a Luis de Gadea Sahajosa (AGM, Not. 7271. fols. 255r/263r). Luis de Gadea Sahajosa, además de ser suegro de Pedro Muñoz y de Francisco Musso Muñoz de Otálora, era cabeza del bando de los Muñoces y yerno del citado Gonzalo Muñoz. Estas prácticas son ciertamente habituales en los Muñoces. La racionalización y concentración del patrimonio fue practicada tanto por Pedro Muñoz de Otálora como por Francisco Musso Muñoz, tal vez con vistas a una posterior unión de las dos líneas mayorazgas de la familia. En 1628, al igual que hizo su hermano, Francisco Musso Muñoz de Otálora compró a Martín de Robles Ferrer una hacienda en el Tornajuelo por precio de 300 ducados (estaba compuesta de fuentes, casas, labor, pajar, colmenar y ejido), situada junto a las propiedades del vínculo de Tarragoya (AGM, Not. 7268, fols. 217r/220v). Los otros grandes terratenientes de Tarragoya y el Tornajuelo eran los Monreal, familia que también 
poseía una torre y una ermita en el mencionado lugar, circunstancia que explica el matrimonio celebrado en 1651 entre Francisco Musso Muñoz de Otálora y María Teresa de Monreal, heredera de Fernando de Monreal y de Ana Donoso. La mayor parte de los bienes vinculados de la familia estaban situados en la cañada de Tarragoya y en el Tornajuelo: el resultado fue la creación de grandes extensiones de tierras o latifundios que coexistieron con el mosaico de parcelas que poseían los labradores y los pequeños propietarios de la villa de Caravaca.

\section{CONCLUSIONES}

Las estrategias de reproducción social empleadas por la familia fueron efectivas desde el punto de vista económico y social, pero el linaje finalmente se perdió en las líneas femeninas y en la ilegitimidad. Pedro Muñoz de Otálora casó en 1627 con Luisa de Gadea, pero tan solo dejaría dos hijas: Juana Clara Muñoz de Otálora, la mayorazga, casada en 1649 en primeras nupcias con Martín de Otálora, señor de las casas de Otálora, y en 1652 con Juan Bautista Muñoz Sáenz de Navarrete, hijo del poderoso secretario Juan Bautista Sáenz de Navarrete. La acumulación de mayorazgos de la familia Muñoz de Otálora era tan importante que el propio Juan Bautista, que llegaría a ser fiscal del Consejo de Castilla tras pasar por la fiscalía del Consejo de Hacienda, por la Real Chancillería de Valladolid y por la sala de hijosdalgo de la Chancillería de Granada, antepuso el Muñoz a su propio apellido, tal y como estipulaban las cláusulas fundacionales. Aunque este tipo de exigencias eran frecuentes, lo cierto es que rara vez se cumplían, de ahí su importancia. La segunda hija, llamada Catalina, contrajo matrimonio en 1651 con Diego de Uribe Yarza, señor de la villa de San Mamés. La descendencia de ambos matrimonios obtendrían títulos nobiliarios: los Uribe consiguieron en la centuria siguiente el título de marqués de San Mamés y los Cañaveral, descendientes por línea femenina de los Muñoz Sáenz de Navarrete, el título de marqueses de Araceli.

Los Muñoz de Otálora afincados en la corte primero perderían la legitimidad y posteriormente la varonía. El capitán Pedro Jacinto Muñoz de Otálora, hijo natural (en realidad parece que era bastardo), de Pedro Jacinto Muñoz de Otálora, caballero de Santiago y caballerizo de la Reina, y de María de Orozco, perdió, como ya hemos indicado, buena parte de los mayorazgos de la familia: se los repartieron entre los Uribe, los Sáenz de Navarrete y los Díaz de Tudanca. Las prácticas de concentración y racionalización del patrimonio servían para gestionar la hacienda de manera más efectiva y para cumplir los objetivos de reproducción social, pero evidentemente no garantizaban la reproducción 
biológica ni tan siquiera la reproducción patriarcal caracterizada por la varonía, la primogenitura y la legitimidad. El patrimonio material y simbólico de los Muñoz de Otálora acabaría finalmente en manos de otras familias.

Árbol genealógico 4. Descendencia del licenciado Alonso Muñoz

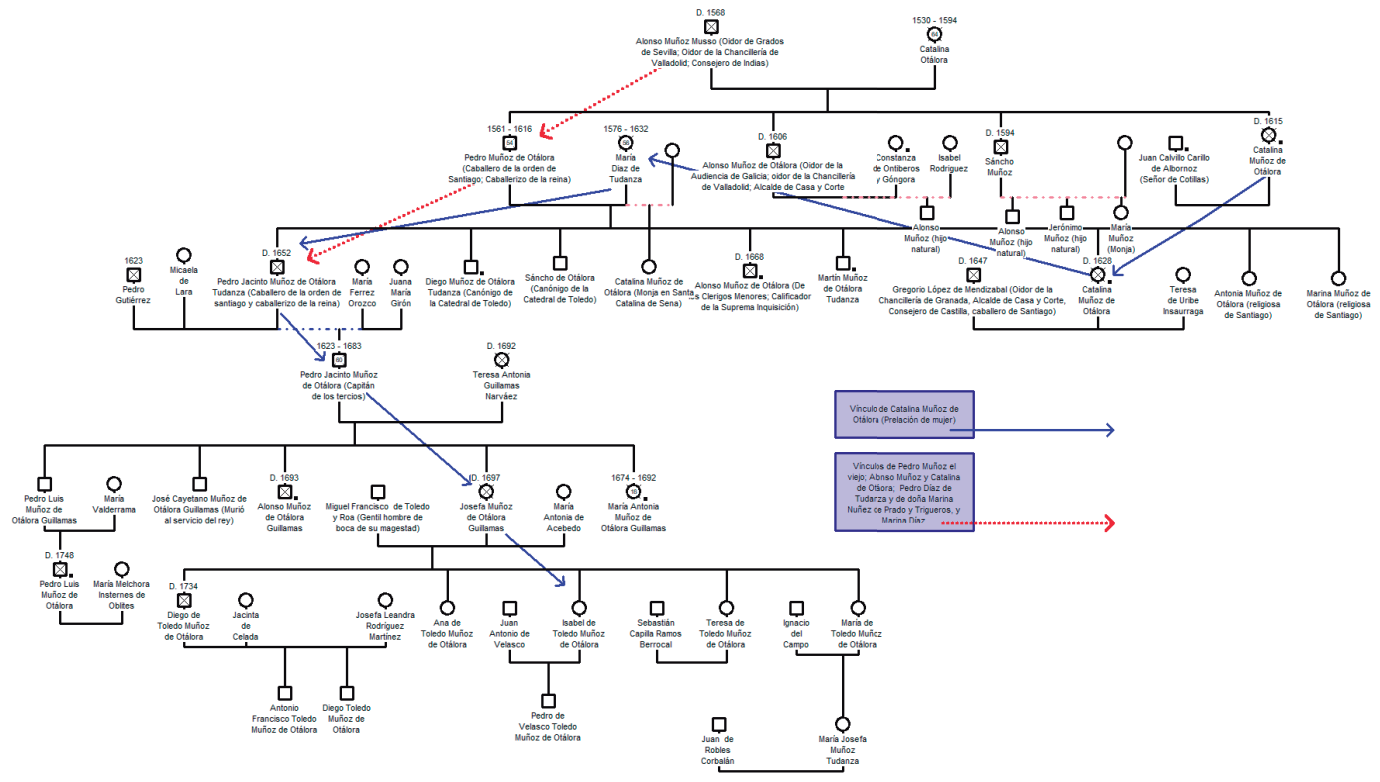

Fuente: Elaboración propia a partir de los registros parroquiales y protocolos notariales de Caravaca.

\section{REFERENCIAS BIBLIOGRÁFICAS}

Aguilera Portales, Lucía y José Antonio Guillén Berrendero. "De sangre, familia y otros conceptos nobiliarios en Castilla y Portugal en los inicios del siglo XVII". Familia, valores y representaciones, coordinado por Joan Bestard Comas y Manuel Pérez García, Universidad de Murcia, 2010, pp. 95-114.

Archivo General de Murcia (AGM). Not. 7002, fols. 32r/34v. Poder para la fundación del convento.

-----. Not. 7003, fols. 80r/ 84v. Escritura de monjía entre Gonzalo Muñoz y el convento.

Not. 7003 , fol. 83 r. 
-----. Not. 7274, fols. 427r/447. Testamento y codicilo de Catalina López Muñoz, viuda de Francisco Musso Muñoz de Otálora.

-----. Not. 7003, fols. 56r/59. Cesión y traspasación de Francisco Musso Muñoz Girón

-----. Not. 7004, fols. 77r/79r.

-----. Not. 7004, fols. 76r/ v. Carta de pago y finiquito del convento de San José a Gonzalo Muñoz.

-----. Not. 7005, fols. 57r/61r. Renuncia de legítima de Catalina Muñoz, monja del Carmen.

-----. Not. 7055, fols. 98r/99r. Obligación de Gonzalo Muñoz con las monjas de Santa Clara.

-----. Not. 7062, fols. 234r/236. Capitulaciones matrimoniales de don Luis de Gadea Sahajosa, hijo de Pedro de Gadea Belmad y de Lucrecia de Sahajosa, y de doña Juana Muñoz, hija de don Gonzalo Muñoz Musso y de doña Luisa Rodríguez.

-----. Not. 7126, fols. 29r/30v. Testamento de Juan Escagedo Musso Muñoz.

-----. Not. 7142, fol. 202r/v. Carta de obligación de Pedro Alcázar Torrecilla.

-----. Not. 7199, fols. 136r/140r. Carta de venta de Francisca Muñoz a Francisco Musso Muñoz de Otálora.

-----. Not. 7221, fols. 57r/58v. Donación a Aldonza Muñoz.

-----. Not. 7268, fols. 80r/85r y 87r/89v.

-----. Not. 7268, fols. 217r/220v. Carta de venta de Martín de Robles a Francisco Musso Muñoz.

-----. Not. 7271. fols. 255r/263r. Carta de venta de Luis de Gadea Sahajosa.

-----. Not. 7274, fols. 427r/447. Testamento y codicilo de Catalina López Muñoz, viuda de Francisco Musso Muñoz de Otálora.

----. Not. 7278 , fols. $1495 \mathrm{r} / 1497 \mathrm{v}$.

-----. Not. 7333, fols. 297r/324v. Profesión de Inés Muñoz

-----. Not. 7348, fol. 194r. Licencia para dar el hábito a Lucrecia, hija de don Luis de Gadea.

-----. Not. 7350, fols. 86r/116r. Testamento de Gonzalo Muñoz.

-----. Not. 7386, fols. 32r/ 35r.Tratados de profesión de Aldonza Muñoz.

----. Not. 7386, fols. 36r.

-----. Not. 7386, fols. 36r/37v. Promesa de dote de monja. 
-----. Not. 7386, fols. 126r/127r. Promesa de dote de monja de Inés Musso.

-----. Not. 7432, fols. 60r/67r. Carta de dote de Catalina de Uribe Yarza, esposa de Francisco Musso Muñoz de Otálora.

Archivo General de Simancas. CME, 130, 34, s. f. Testamento de Pedro Muñoz de Otálora, caballero de la orden de Santiago.

Archivo Histórico Nacional (AHN).OM-Religiosas_Santiago, Exp. 466. Expediente de Marina y Antonia Muñoz de Otálora.

----. OO_MM. AHT. Exp. 15959, s. f.

----. OO_MM. AHT. Exp. 9412., s. f.

----. CONSEJOS, 25857. Exp. 5. 230r/v.

Archivo Histórico Protocolos Notariales de Toledo. T. 16939, fols. 450r/453v. Testamento de Sancho Muñoz de Otálora, canónigo de la Catedral de Toledo.

Archivo Histórico Protocolos Notariales de Madrid. T. 2054, fols. 235r/250r. Testamento de María Díaz de Tudanca.

Archivo Municipal de Caravaca (AMC). Fondos reproducidos. Libro de las profesiones de monjas del Carmen de Caravaca, fol. 51r.

-----. Fondos reproducidos. Libro de las profesiones, fol. 17r. Memoria de las prioras del convento.

-----. Fondos reproducidos. Libro de las profesiones, fol. 42r.

Arranz Guzmán, Ana. "Celibato eclesiástico, barraganas y contestación social en la Castilla bajomedieval". Espacio, Tiempo y Forma, serie III. Historia Medieval. T. 21, 2008, pp. 13-39. https://doi.org/10.5944/ etfiii.21.2008.3775

Bestard, Joan. "La estrechez del lugar. Reflexiones en torno a las estrategias matrimoniales cercanas". Poder, Familia y consanguinidad en la España del Antiguo Régimen, coordinado por Francisco Chacón Jiménez y Juan Hernández Franco, Anthropos, 1992, pp.107-156.

Blutrach Jelín, Carolina. "Memoria y vínculos familiares: la fragmentación y sepultura del cuerpo del III conde de Fernán Núñez (1644-1721)”. Familia, valores y representaciones, editado por Joan Bestard y compilado por Manuel Pérez García, Universidad de Murcia, 2010, pp. 137-153.

Catalán Martínez, Elena. "El clero ante la crisis del siglo XVII. Conflictos y estrategias". Tiempos moderno: Revista Electrónica de Historia Moderna, vol. 7, no. 20, 2010, pp.1-35. http://www.tiemposmodernos.org/tm3/index.php/tm/article/view/215 
Chacón Jiménez, Francisco y Josefina Méndez Vázquez. "Miradas sobre el matrimonio en la España del último tercio del siglo XVIII". Cuadernos de Historia Moderna, vol. 32, 2007, pp. 84-85. https://revistas.ucm.es/index.php/CHMO/article/view/CHMO0707110061A

Chacón Jiménez, Francisco. "La historia de la familia. Debates metodológicos y problemas conceptuales". Revista Internacional de Sociología, tercera época, no. 11, mayo-agosto 1995, pp. 5-20.

-----. "Familia, casa y hogar. Una aproximación a la definición y realidad de la organización social española (siglos XIII-XX)". Espacios sociales, universos familiares. La familia en la historiografia española, editado por Francisco Chacón Jiménez y Juan Hernández Franco, Editum, Universidad de Murcia, 2007, pp. 51-66.

De Jesús, Teresa. Libro de las fundaciones de las hermanas descalças Carmelitas, Bruselas, 1610.

Devillard, Marie-Jose. "Parentesco y estrategias de reproducción social". Agricultura y sociedad, no. 52, 1989, pp. 143-206.

Domínguez Ortiz, Antonio. Las clases privilegiadas en el Antiguo Régimen. Istmo, 1995.

Egido, Teófanes. "Santa Teresa y sus cartas. Historia de los sentimientos". Hispania Sacra, LXVII, 2015, pp. 401-428. https://doi.org/10.3989/ hs.2015.012

Ferrer Alos, Llorenç. "Sistema hereditario y reproducción social en Cataluña", Sistema hereditario y reproducción social en Cataluña", Mélanges de l'Ecole française de Roma, Italie et Méditerranée, 1998, Tomo 110, pp. 53-57.

-----. "Segundones y actividad económica en Cataluña (siglos XVIII-XIX). Reflexiones a partir de la familia Berenguer de Artés". Revista de Demografía Histórica, XXI, II, segunda época, 2003, pp. 93-128. https://www.adeh.org/revista/2003,\%202/Ferrer\%20i\%20Alos\%20p.93126.pdf

Gacto Fernández, Enrique. "Entre la debilidad y la simpleza. La mujer ante la ley". Historia 16, no. 145, 1988, pp.24-32.

García de Bertolacci, Ángela Francisca. "La experiencia espiritual en Santa Teresa de Jesús: Riqueza y actualidad". Congreso Interuniversitario Santa Teresa de Jesús, maestra de vida, coordinado por Isabel Pérez Cuenca, María Isabel Abradelo de Usera y María Teresa Cid Vázquez, 2015, pp. 523-637. 
Gausse, Jean-Marie. "Mariages de proches parents (XVIé-XXé siécle). Esquisse d'une conjoncture". Le modéle familial Europeen. Normes, déviances, contrôle du pouvoir, Collection de L'Ecole Française de Rome, 90, 1986, pp. 31-61.

Ghirardi, Mónica. "Iglesia, sexualidades y estrategias familiares de selección matrimonial en Córdoba en el siglo XVIII". Cuestiones de Familia a través de las fuentes, editado por Mónica Ghirardi, Universidad Nacional de Córdoba, 2005, pp. 141-188.

Goody, Jack. La familia europea. Ensayo histórico antropológico. Crítica, 2001. Hernández Franco, Juan y Sebastián Molina Puche. "Mantenerse arriba. Las familias dominantes en la Castilla Moderna". Espacios sociales, universos familiares. La familia en la historiografia española, editado por Francisco Chacón Jiménez y Juan Hernández Franco, Editum, Universidad de Murcia, 2007, pp. 219-235.

Hernández, Mauro. A la sombra de la Corona. Poder local y oligarquía urbana (Madrid, 1606-1808), Siglo XXI editores, 1995.

Irigoyen López, Antonio. "Bajo el manto de la iglesia. Clero y familia en España durante la Edad Moderna". Espacios sociales, universos familiares: la familia en la historiografía española: XXV aniversario del seminario Familia y élite de poder en el Reino de Murcia, siglos XV-XIX, editado por Francisco Chacón Jiménez y Juan Hernández Franco, Universidad de Murcia, 2007, pp. 245-259.

-----. "Carrera eclesiástica, servicio doméstico y curso de vida (Murcia, siglo XVIII)". Revista de historia moderna: Anales de la Universidad de Alicante, ejemplar dedicado a: Curso de vida y reproducción social en España y en Europa en la Edad Moderna, no. 34, 2016, pp. 279-295. https://doi.org/10.14198/RHM2016.34.13

-----. Entre el cielo y la tierra, entre la familia y la institución: el Cabildo de la Catedral de Murcia en el siglo XVII. Universidad de Murcia, 2001.

Levi, Giovanni. La herencia inmaterial: la historia de un exorcista piamontés del siglo XVIII. Nerea, 1990

Marín Cobos, Almudena. "Clérigos regulares menores. El convento de los Clérigos Menores". Fondos y procedencias: Bibliotecas en la Biblioteca de la Universidad de Sevilla: exposición virtual 2013, coordinado por Eduardo Peñalver Gómez, Universidad de Sevilla, 2013, pp. 251-254. 
Melgares Guerrero, José Antonio y María Amparo Martínez Cuadrado. Historia de Caravaca a través de sus monumentos. Caja de Ahorros Provincial de Murcia, 1981.

Manero Sorolla, María del Pilar. "Santa Teresa y Felipe II". Actas del V Congreso Internacional de la Asociación Internacional Siglo de Oro (AISO), coordinado por Christpoh Strosetzli, 2001, pp. 826-834.

Molina Puche, Sebastián. Poder y familia: Las elites locales del corregimiento Chinchilla-Villena en el siglo del Barroco. Universidad de Castilla La Mancha, Universidad de Murcia, 2007.

Monteiro, Nuno Gonçalo. "Casamento, celibato e reprodução social: a aristocracia portuguesa nos séculos XVII e XVIII”. Analises Social, V. XXVIII, no. 4 e 5, 123-124, 1993, pp. 921-950.

Morand, Frederique. "El papel de las monjas en la sociedad española del setecientos". Cuadernos de historia moderna, no. 29, 2004, pp. 45-64. https://revistas.ucm.es/index.php/CHMO/article/view/CHMO0404110045A

Morgado García, Arturo Jesús. "El clero en la España de los siglos XVI y XVII: estado de la cuestión y últimas tendencias". Manuscrits: Revista d'història moderna, no. 25, 2007, pp. 75-100. https://ddd.uab.cat/pub/ manuscrits/02132397n25/02132397n25p75.pdf

Pérez Morera, Jesús. "La república del claustro: jerarquía y estratos sociales en los conventos femeninos". Anuario de Estudios Atlánticos, no. 51, 2005, pp. 327-389. http://anuariosatlanticos.casadecolon.com/index.php/aea/ article/view/881

Pizarro Llorente, Henar. "Los miembros del cabildo de la Catedral de Toledo durante el arzobispado de Gaspar de Quiroga (15771594)". Hispania Sacra, Vol. 62, no. 126, 2010, pp. 563-619. https://doi.org/10.3989/hs.2010.v62.1126.259

Ramos Cobano, Cristina. "Las huellas de Santa Teresa de Jesús. El legado espiritual y familiar de una monja reformadora". Andalucía en la Historia, no. 21, 2008, pp. 70-73. https://dialnet.unirioja.es/servlet/ articulo?codigo $=2795113$

-----. Familia, Poder y representación en Andalucía. Los Cepeda entre el Antiguo y el Nuevo Régimen (1700-1850). Tesis doctoral dirigida por Manuel José de Lara Ródenas, Universidad de Huelva, 2012.

Reher, David Sven. "Household and family on the Castilian meseta: the province of Cuenca from 1750-17902". Journal of Family History, no. 13, 1, pp. 59-75. https://doi.org/10.1177\%2F036319908801300104 
Rodríguez Sánchez, Ángel. "El poder y la familia. Formas de control social y consanguinidad en la Extremadura de los tiempos modernos". Poder, familia y consanguinidad en la España del Antiguo Régimen, editado por Francisco Chacón Jiménez, y Juan Hernández Franco, Anthropos Editorial, 1992, pp. 15-34.

Sánchez González, Ramón. Iglesia y sociedad en la Castilla moderna: el Cabildo catedralicio de la Sede Primada (siglo XVII). Cuenca, 2000.

Sequeira, Jacintha Verónica. "Saint Teresa: a woman of prayer and a model for new evangelization". Congreso Interuniversitario Santa Teresa de Jesús, maestra de vida, coordinado por Isabel Pérez Cuenca, María Isabel Abradelo de Usera y María Teresa Cid Vázquez, 2015, pp. 1094-1108.

Stickler, Alfonso M. "El celibato eclesiástico. Su historia y sus fundamentos teológicos". Scripta theologica: Revista de la Facultad de Teología de la Universidad de Navarra, vol. 25, fasc. 1, 1994, pp. 13-78. https://revistas.unav.edu/index.php/scripta-theologica/article/view/15237/14917

Stone, Lawrence. Familia, sexo y matrimonio en Inglaterra. 1500-1800. Fondo de Cultura económica, 1990.

Vigil, Mariló. "Conformismo y rebeldía en los conventos femeninos de los siglos XVI y XVII". Religiosidad femenina, expectativas y realidades (siglos VIII-XVIII), editado por Ángela Muñoz Fernández y $\mathrm{M}^{\mathrm{a}}$ del Mar Grañacida, Asociación Cultural Al-Mudayna, 1991, pp. 169-170. 